\title{
Pondering parotid masses
}

\author{
Mark A Miller MD
}

A 49-year-old, human immunodeficiency virus (HIV)infected, Haitian-born woman presented with a left facial mass that she had noticed for the previous eight weeks. She was known to have been HIV-seropositive for the previous 11 years and had been on multiple antiretroviral therapies. Her past medical history was also significant for hypertension, disseminated varicella zoster virus and recurrent oral and buttock Herpes simplex episodes. She was taking the following medications at the time of her presentation with the facial mass: stavudine, lamivudine, didanosine, nelfinavir mesylate, famciclovir, hydrochlorothiazide and cotrimoxazole. She had no complaints of fever, chills, sweats, weight loss or anorexia. She denied any pain, redness or warmth at the site of the facial swelling. Her most recent CD4 lymphocyte count was 336 cells $/ \mu \mathrm{L}$, with an HIV viral load of $\log _{10} 2.6$ copies $/ \mathrm{mL}$.

Physical examination revealed a $4 \mathrm{~cm}$ fluid-filled mass in the left parotid gland. There was no detectable induration, redness, warmth or tenderness, and no associated adenopathy.
The rest of the examination was unremarkable. An aspirate of the mass was performed under sterile conditions and yielded $30 \mathrm{~mL}$ of turbid, yellow liquid. A Gram stain revealed no neutrophils, scant mononuclear cells and no visible organisms. An acid-fast stain was negative as well. Routine, mycobacterial and fungal cultures showed no growth. Cytological analysis showed scant reactive lymphocytes and no malignant cells.

The patient was not given therapy and was observed for another two months. The fluid reaccumulated in the left parotid gland, and the patient's only complaint concerned the unsightly appearance of the mass. The lesion was again aspirated for $30 \mathrm{~mL}$ of fluid and this time, the fluid had a turbid, brown appearance. All laboratory results were identical to the results from the first aspirate.

What is your diagnosis, and how would you treat this patient?

Continued on page 115 
Continued from page 107

\section{DIAGNOSIS}

This HIV-infected woman was affected with benign lymphoepithelial parotid cysts (BLPCS). This condition is associated with HIV infection in both adults and children (1-3). It may present unilaterally or bilaterally. Although sometimes painful, these cysts are usually not tender and noninflammatory. Most patients only complain about the unpleasant appearance of the mass. Although a parotid mass in any individual may be neoplastic in nature, parotid tumours are very rare in HIV-infected persons.

The exact etiological nature of BLPCs is unknown. However, the current hypothesis is that lymphoid hyperplasia in intraparotid lymph nodes causes partial or complete duct obstruction, leading to fluid-filled cysts (3). The reason that the parotid glands (and not other salivary glands) are involved in BLPCs arises from the fact that only the parotid gland has sequestered lymph nodes inside the gland capsule. These lymph nodes are incorporated inside the parotid gland during embryological development. Other reasons for lymphoid proliferation in the parotid gland may also play a role (ie, HIV [4] or other viral infections).

Antiretroviral therapy usually leads to the regression of BLPCs (1), but the appearance of residual cysts may become a source of distress for the patient. Treatment modalities that have been attempted include repeated needle aspiration, superficial parotidectomy, low dose radiotherapy $(5,6)$ and laser ablation. An interesting new approach is sclerotherapy, completed by aspiration and subsequent injection of doxycycline intralesionally $(3,7)$. Insufficient experience with this latter therapy precludes its routine recommendation at the present time, but it may be the least invasive treatment approach for refractory BLPCs.

In conclusion, diagnostic tests (including cultures of aspirated contents to rule out rare infections [8]) should be performed on all parotid masses in HIV-infected individuals. The most common diagnosis of cystic parotid lesions is BLPCs, which usually respond to antiretroviral therapy. No optimal therapy has yet been determined for refractory cysts, but doxycycline sclerotherapy seems to be a promising approach.

\section{REFERENCES}

1. Craven DE, Duncan RA, Stram JR, et al. Response of lymphoepithelial parotid cysts to antiretroviral treatment in HIV-infected adults. Ann Intern Med 1998;128:455-9.

2. Mandel L, Hong J. HIV-associated parotid lymphoepithelial cysts. J Am Dent Assoc 1999;130:528-32.

3. Suskind DL, Tavill MA, Handler SD. Doxycycline sclerotherapy of benign lymphoepithelial cysts of the parotid: a minimally invasive treatment. Int J Pediatr Otorhinolaryngol 2000;52:157-61.

4. Vicandi B, Jimenez-Heffernan JA, Lopez-Ferrer P, et al. HIV-1 (p24)-positive multinucleated giant cells in HIV-associated lymphoepithelial lesion of the parotid gland. A report of two cases. Acta Cytolog 1999;43:247-51.

5. Goldstein J, Rubin J, Silver C, et al. Radiation therapy as a treatment for benign lymphoepithelial parotid cysts in patients infected with HIV-1. International Conference on AIDS. Florence, June 16 to 21, 1991. (Abst MB2266)

6. Kooper DP, Leemans CR, Hulshof MC, Claessen FA, Snow GB. Management of benign lymphoepithelial lesions of the parotid gland in HIV-positive patients. Eur Arch Otorhinolaryngol 1998;255:427-9.

7. Lustig LR, Lee KC, Murr A, Deschler D, Kingdom T. Doxycycline sclerosis of benign lymphoepithelial cysts in patients infected with HIV. Laryngoscope 1998;108:1199-205.

8. Knee TS, Ohl CA. Salmonella parotitis with abscess formation in a patient with human immunodeficiency virus infection. Clin Infect Dis 1997;24:1009-10. 


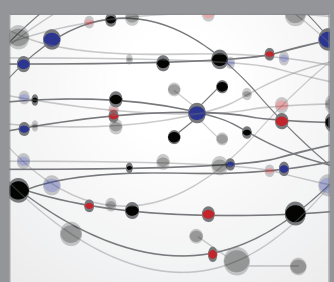

The Scientific World Journal
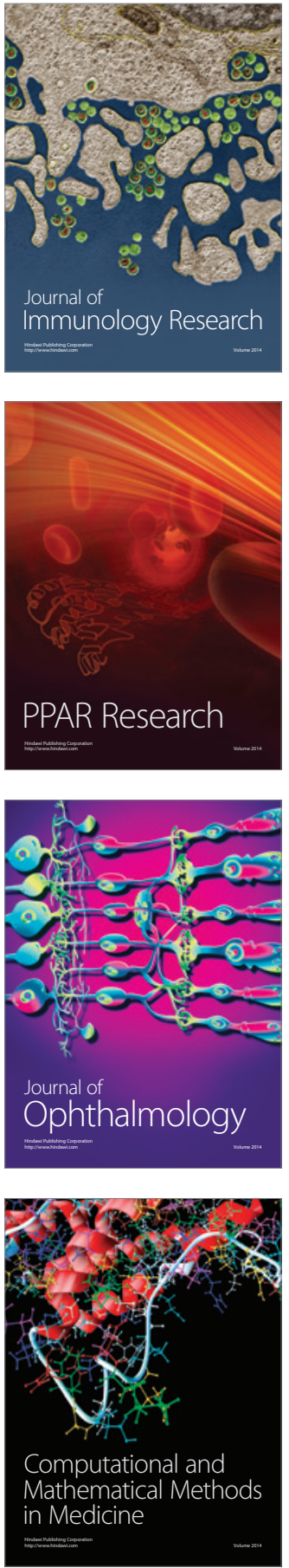

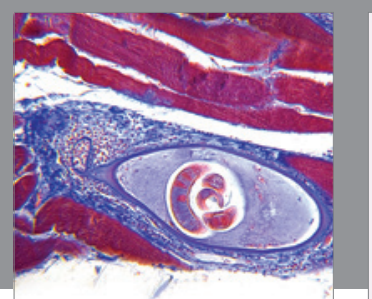

Gastroenterology Research and Practice

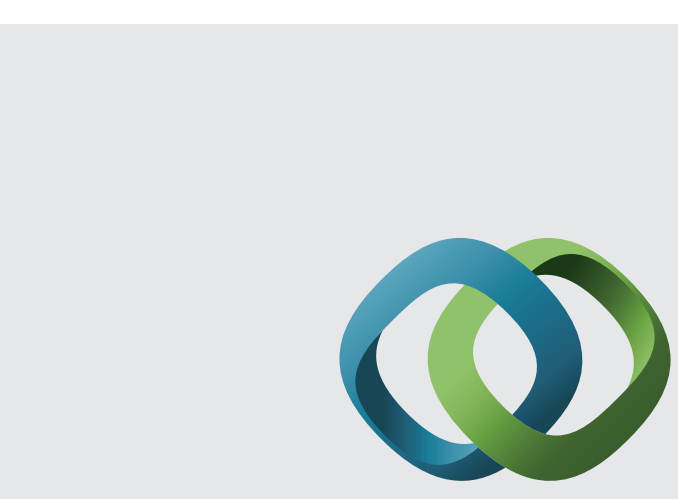

\section{Hindawi}

Submit your manuscripts at

http://www.hindawi.com
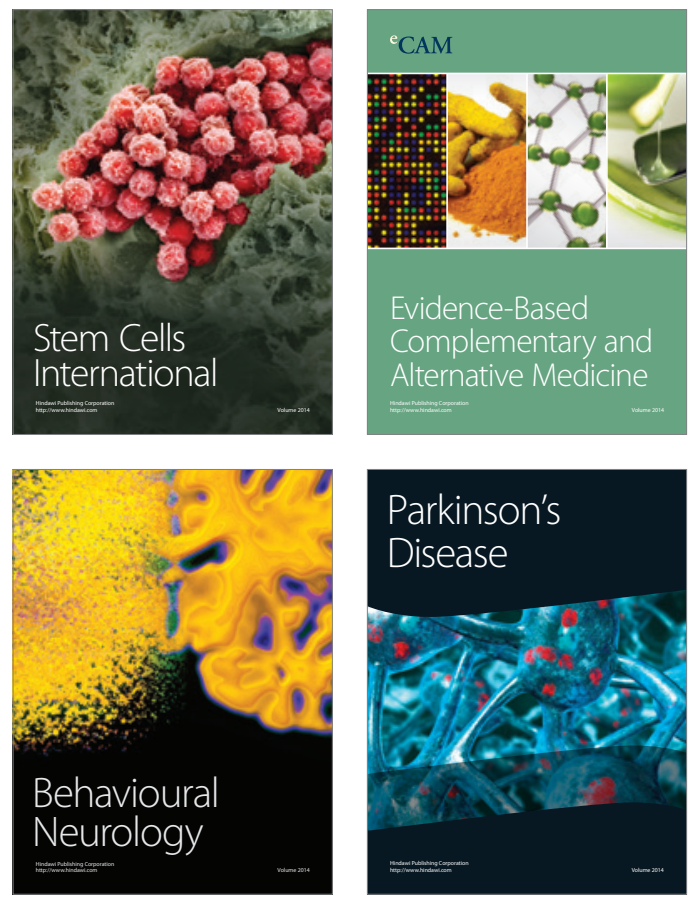
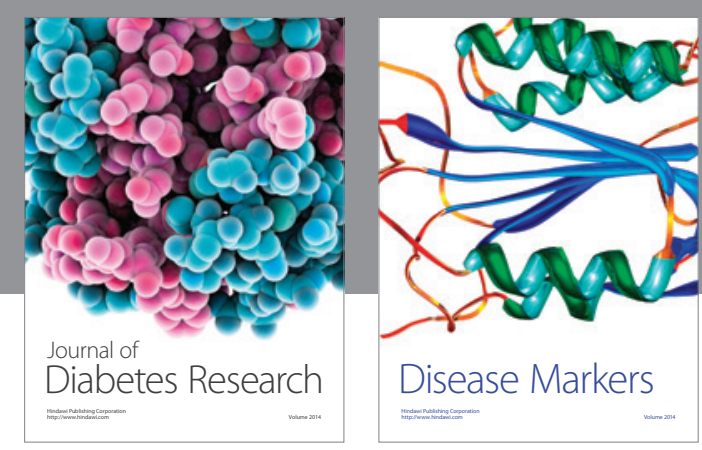

Disease Markers
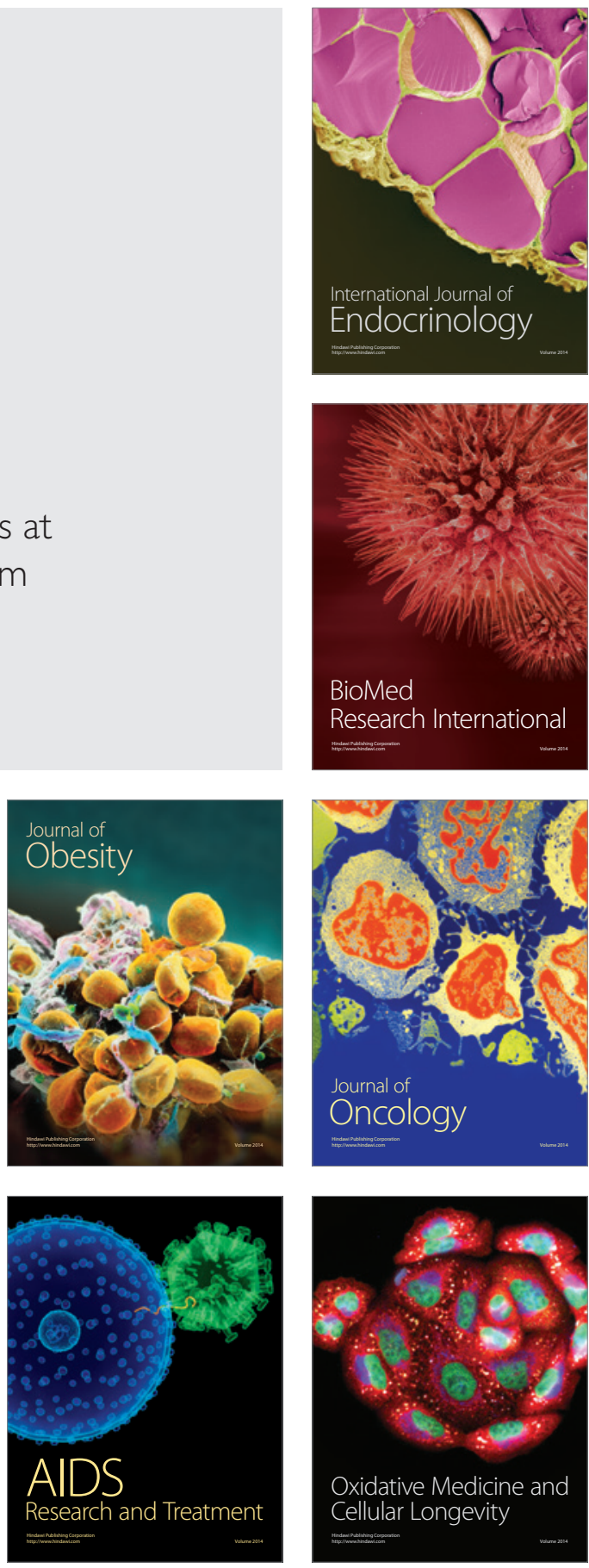